\title{
USO DA CLASSIFICAÇÃO DA VEGETAÇÃO NO MANEJO INTEGRADO ENTRE ÁRVORES E REDES DE DISTRIBUIÇÃO DE ENERGIA ELÉTRICA
}

\author{
Altamir Fernandes de Oliveira ${ }^{1}$, José Aldo Alves Pereira², Sivério José Coelho³ \\ Gabriel de Assis Pereira ${ }^{4}$
}

\section{RESUMO}

Os métodos de classificação na descrição e análise da vegetação são muito úteis para o conhecimento geral de determinada área a ser estudada, pois permite verificar padrões e inter-relações entre comunidades vegetais que visualmente seria impossível predizer. A vegetação, devido ao seu grau de importância ambiental, é o foco de vários trabalhos com grande valor na comunidade científica. Essas pesquisas inevitavelmente levam em consideração algumas técnicas de classificação aliadas a outros métodos de análise. $O$ presente estudo teve como objetivo uma abordagem inicial dos métodos de classificação da vegetação na arborização urbana com propostas para seu uso por companhias energéticas que visam à compatibilização entre suas redes de distribuição de energia elétrica e as árvores no meio urbano. O método TWISPAN resultou em análises favoráveis às concessionárias de energia elétrica, uma vez que permitiu separar grupos de árvores com atributos chaves para a tomada de decisão usual destas companhias, como a poda de árvores de grande porte que estão em conflito com a rede.

Palavras-chave: Diversidade; Manejo da vegetação; Arborização urbana.

Recebido em 28.09.2012 e aceito em 06.05.2015

1 Biólogo, Administrador Público, Doutorando em Engenharia Florestal pelo Programa de Pós-Graduação em Engenharia Florestal da Universidade Federal de Lavras - UFLA-MG. Campus Universitário, Caixa Postal 3037. Lavras-MG. E-mail: altamirf3@gmail.com.

2 Engenheiro Florestal, Professor Doutor do Departamento de Engenharia Florestal da Universidade Federal de Lavras UFLA-MG. Câmpus Universitário, Caixa Postal 3037. Lavras-MG. E-mail: j.aldo@dcf.ufla.br.

3 Agrônomo, Professor Doutor do Departamento de Fitotecnia da Universidade Federal de Lavras - UFLA-MG. Campus Universitário, Caixa Postal 3037. Lavras-MG. E-mail: sjcoelho65@gmail.com.

4 Engenheiro Florestal, Mestrando em Engenharia Florestal pelo Programa de Pós-Graduação em Engenharia Florestal da Universidade Federal de Lavras - UFLA-MG. Campus Universitário, Caixa Postal 3037. Lavras-MG. E-mail: gabriel_assispereira@hotmail.com. 


\title{
THE USE OF VEGETATION CLASSIFICATION TO THE TREES AND NETWORK DISTRIBUTION OF ELECTRICITY INTEGRATED MANAGEMENT
}

\begin{abstract}
The classification methods in the vegetation description and analysis are very useful for the general knowledge of a particular area to be studied. They allow verifying patterns and interrelationships between plant communities that would be impossible to predict without the methods. The vegetation, because of its degree of environmental importance, is the focus of several studies with large value in the scientific community. These researches will inevitably take into account some classification techniques combined with other methods of analysis. The aim of this study was to describe the theme and include an innovation: the methods of classification of vegetation in urban forestry with proposals for its use by energy companies that aim to compatibility their power grids and trees in the urban area. The TWISPAN method lead a favorable analyze to the electric utilities, since it allowed the separation of groups of trees with key attributes for usual decision making of these companies, such as large trees pruning that are in conflict with the power grid.
\end{abstract}

Keywords: Classification; Vegetation Methods; Urban forestry; Power grids.

\section{INTRODUÇÃO}

A utilização de chaves dicotômicas de hierarquia na identificação de plantas são ferramentas essenciais para a classificação botânica e requer muitos anos de prática. Esse uso se baseia em presença e ausência de algumas propriedades de plantas, tais como morfologia e fisiologia, havendo a necessidade de uma hierarquia de nomenclatura de taxonomia (KENT; COKER, 1992).

Segundo Kent e Coker (1992), para um trabalho bem conceituado de classificação da vegetação, além de técnicas florestais e prática de campo, é necessário um bom conhecimento botânico visando a identificação correta de espécies para o estudo evitando refazer a pesquisa. Caso não sejam observados, esses problemas podem inviabilizar o uso 
dos métodos de classificação da vegetação e, consequentemente comprometer o resultado final.

A classificação ecológica é definida, segundo Dolan e Parker (2005), como um método que descreve a estrutura do ecossistema, o qual visa identificar relações entre fatores bióticos e fatores abióticos.

Por meio de uma descrição de objetos multivariada, a análise de agrupamento se torna uma ferramenta bastante útil e podem ser combinados com vários índices de semelhança. Uma vez que os algoritmos têm caráter objetivo e muitas vezes as escolhas do pesquisador são subjetivas, deve-se observar que independente disso as técnicas de análise de agrupamento sempre resultarão em grupos distintos, mesmo que não fique claro (PILLAR, 1999).

Geralmente a organização de dados de vegetação segue a estrutura de uma matriz retangular em que as colunas são reservadas às unidades de amostragem e as linhas os atributos. Em atributos de sistemas naturais, as variáveis podem ser agrupadas por tipo, e estas podem ser: espaço tempo, espaço biológico, espaço físico em duas ou três dimensões e espaço ambiental. Alguns espaços são abstratos e utilizam-se tabelas de dados com o preenchimento dos atributos a serem avaliados, o que depende do objetivo do trabalho (WILDI, 2010).

Pacotes de software provêm melhor acesso aos dados sendo estes mais bem interpretados quando se incluem os atributos espaciais e temporais no topo das tabelas a serem analisadas, como é feito em fitossociologia tradicional. De modo geral os dados bióticos são adicionados na forma de listas de espécies (WILDI, 2010).

A classificação da vegetação engloba uma vasta gama de técnicas multivariadas de análises com o objetivo de agrupar conjunto de indivíduos, que pode ser parcelas ou amostras de vegetação, baseados em seus atributos (composição florística, por exemplo). 0 resultado final da classificação origina um conjunto de grupos onde cada indivíduo apresenta maior semelhança com um outro do mesmo grupo do que com qualquer indivíduo de um grupo diferente (KENT; COKER, 1992).

Segundo Chuman e Romportl (2010), um método de classificação da vegetação pode ser subjetivo e objetivo, sendo esse último o mais utilizado em abordagens metodológicas. O sensoriamento remoto, software GIS e computadores cada vez mais potentes oferecem novos meios de classificar paisagens menos subjetivas e contribuem para que a qualidade e a disponibilidade dos trabalhos.

As técnicas de classificação têm o objetivo de reduzir e explorar dados de vegetação e buscam a detecção de padrões possíveis e ordenação de grupos de dados. Os métodos 
de classificação são considerados métodos de análise indireta de gradientes ambientais e trabalham com uma única matriz de dados, a matriz de vegetação, seja ela de presença ou ausência ou de densidade. As inferências sobre os efeitos do ambiente são feitas a posteriori, de modo indireto, comparando os resultados com avaliações qualitativas ou correlacionando, através de cálculos de quocientes de correlação, os autovalores das espécies ou parcelas com variáveis ambientais coletadas em campo (KENT; COKER, 1992).

De acordo com Felfili (2007), atualmente algumas técnicas de classificação são utilizadas e os métodos pioneiros de classificação foram os subjetivos, baseados em arranjos manuais de dados florísticos em tabelas, como por exemplo os métodos chamados Relevé e Zurich-Montpellier. Já entre os métodos de classificação numérica ou objetiva, o TWISPAN (Two Way Indicator Species Analysis) é o mais utilizado desde sua criação. Ele é um método hierárquico, divisível e politético, ou seja, tem fundamento no refinamento progressivo de um único eixo obtido por um método chamado ordenação de médias recíprocas.

O TWISPAN funciona a partir do princípio de que "para um grupo de amostras que constituem um tipo de comunidade, haverá um grupo correspondente de espécies que caracterizam aquele tipo, denominadas espécies indicadoras", o que deixa o método bastante útil quando se tem a necessidade de identificação de espécies que representam comunidades específicas (FELFILI, 2007).

Neste método utilizam-se dados de presença e ausência, porcentagem de cobertura vegetal, abundância, volume, dentre outros atributos. Seu funcionamento se baseia em presença e ausência de espécies em função das parcelas que estas ocorrem e vice-versa. Porém, os dados quantitativos são transformados em amostras artificiais ou variáveis categóricas, chamadas "falsas espécies" (pseudospecies), utilizadas em análises qualitativas (FELFILI, 2007).

Segundo Felfili (2007), o TWISPAN se torna um método bastante eficiente nas análises de vegetação, pois não só classifica as unidades amostrais baseadas nas espécies, como constrói e ordena tabelas para esses dois atributos e "por se tratar de uma técnica hierárquica, os resultados podem ser expressos em forma de dendrograma, o que também facilita a interpretação dos resultados".

Prever grupos utilizando estatística multivariada é de grande importância nas ciências ecológicas e biológicas. Durante os anos os cientistas desenvolveram estratégias para os grupos compostos por genes, indivíduos ou comunidades. Em estudos de ecologia a presença e abundância das espécies por unidades de amostragem tem se tornado um critério muito importante para identificação quantitativa de comunidades diferentes. Entre as 
técnicas mais utilizadas estão o TWISPAN e o Método de Valor de Indicador (IVM) de Dufrêrne e Legendre (DAI; PAGE; DUFFY, 2006).

Estudos de similaridade florística em arborização urbana não são comuns atualmente. Alguns autores têm utilizado métodos de agrupamento para a análise da composição florística de cidades, bairros, praças, universidades, dentre outros locais. Um exemplo é o trabalho de Cupertino e Eisenlohr (2013), que analisaram matrizes de presença e ausência de espécies em levantamentos florestais urbanos de universidades brasileiras. Os autores utilizaram o método UPGMA, com o coeficiente de similaridade de Sørensen que dá maior peso às espécies comuns. Um dos resultados do trabalho foi a grande temática discutida em congressos e seminários de arborização urbana, a utilização em massa de árvores de origem exótica. Os resultados demonstraram que a quantidade de espécies exóticas utilizadas na malha urbana ainda é elevada e aponta que o país tem grande capacidade e variedade de espécies para compor o rol dos indivíduos plantados no ambiente urbano.

Segundo Rocha, Leles e Neto (2004), a arborização urbana exerce numerosas funções, possuindo vários usos e há relatos de que é um tema de bastante interesse, visto que a presença de arbustos e árvores nas cidades melhoram o clima, servem de barreiras contra ventos, dão sombra, embelezam e diminuem a poluição. É muito considerável que a arborização influencia na melhora física e mental do homem da cidade. Nesse sentido a avaliação dos indivíduos arbóreos urbanos se faz necessária para garantir a sua sobrevivência, por meio de inventários que demonstram o patrimônio arbustivo do município. Esse levantamento é valioso para a administração pública, uma vez que fornece dados para um correto manejo da arborização, como necessidades de poda, tratamentos fitossanitários, remoção e plantios dentre outras intervenções.

Uma razão preponderante para a realização de podas em árvores urbanas, é a necessidade de garantir a coexistência harmônica, sem conflitos, da arborização com as redes de distribuição de energia elétrica. Essa coexistência é necessária, pois ambos os serviços são imprescindíveis: a energia elétrica pelo conforto, segurança e todas as facilidades que proporciona a vida moderna, e a arborização pela importância que tem para a qualidade de vida humana (SANTOS, 2000)

Sendo assim, para a pesquisa optou-se por utilizar o método de classificação objetiva TWISPAN, o qual ainda não tem sido explorado pelos pesquisadores da área de manejo de vegetação em ambientes urbanos, sendo considerado um método com potencial inovador. Logo, o objetivo deste foi efetuar uma análise estatística de dados de vegetação urbana localizada debaixo de redes de distribuição de energia elétrica. 


\section{MATERIAIS E MÉTODOS}

\section{Variáveis a partir dos estudos feitos pela Cemig}

O estudo foi realizado com dados fornecidos pela Companhia Energética de Minas Gerais (CEMIG), por meio do Programa Especial de Manejo Integrado de Árvores e Redes (PREMIAR).

Este programa tem como objetivo conduzir todas as políticas da empresa voltadas para o manejo da arborização urbana junto a sistemas elétricos, sempre com foco na redução dos conflitos entre as árvores e a rede elétrica. O Premiar também busca garantir a qualidade do fornecimento da energia elétrica, implementar programas de manejo de vegetação e promover a poda de árvores com a frequência e qualidade necessárias para evitar a interferência com a rede elétrica (CEMIG, 2012).

Os dados fornecidos pela empresa são referentes à planilha de serviços do ano de 2010, em que são avaliados diversos atributos das árvores para se chegar a uma conclusão do serviço a ser executado, podendo ser: poda, supressão, substituição ou adequação ambiental (adequação de rede elétrica a fim de manter a integridade do espécime). Foram diversos os atributos avaliados para se chegar à conclusão do serviço, porém foi feito um filtro para selecionar aqueles mais interessantes ao estudo proposto de classificação da vegetação urbana.

As análises foram realizadas segundo programa PCOrd para Windows $(98,00, \mathrm{ME}$, $\mathrm{NT}, \mathrm{XP}$, Vista, e 7) que tem como base análises multivariadas de dados ecológicos, em sua versão 6.

O PCOrd disponibiliza análises multivariadas de dados ecológicos plotados em planilhas tipo Excel ${ }^{\circledR}$. A sua ênfase está nas ferramentas não paramétricas, representação gráfica, testes de randomização e intervalos de confiança para análises de dados de comunidades. Este programa oferece muitas técnicas de classificação e ordenação que não são disponíveis em pacotes estatísticos, como a CCA, DCA, Análise de Espécies Indicadoras, testes completos e parciais de Mantel, MRPP, PCoA, perMANOVA, RDA, análises de agrupamento two-way, TWISPAN, índices de diversidade, listas de espécies, dendrogramas, dentre outros métodos. Grandes grupos de dados podem ser analisados e muitas operações aceitam uma matriz de 32.000 linhas e 32.000 colunas e mais de 536.848.900 elementos disponibilizados. A terminologia é realizada segundo critérios ecológicos (MjM, 2012). 
Assim, foi feita uma primeira tentativa de se classificar os indivíduos encontrados na Região Administrativa Barreiro - Região Metropolitana de Belo Horizonte (RMBH) analisando-se a planilha de serviços de 2010 cedida pelo Premiar (Figura 1).

Figura 1. Planilha Premiar de serviços/vistorias executados em 2010

Figure 1. Premiar worksheet services/surveys performed in 2010

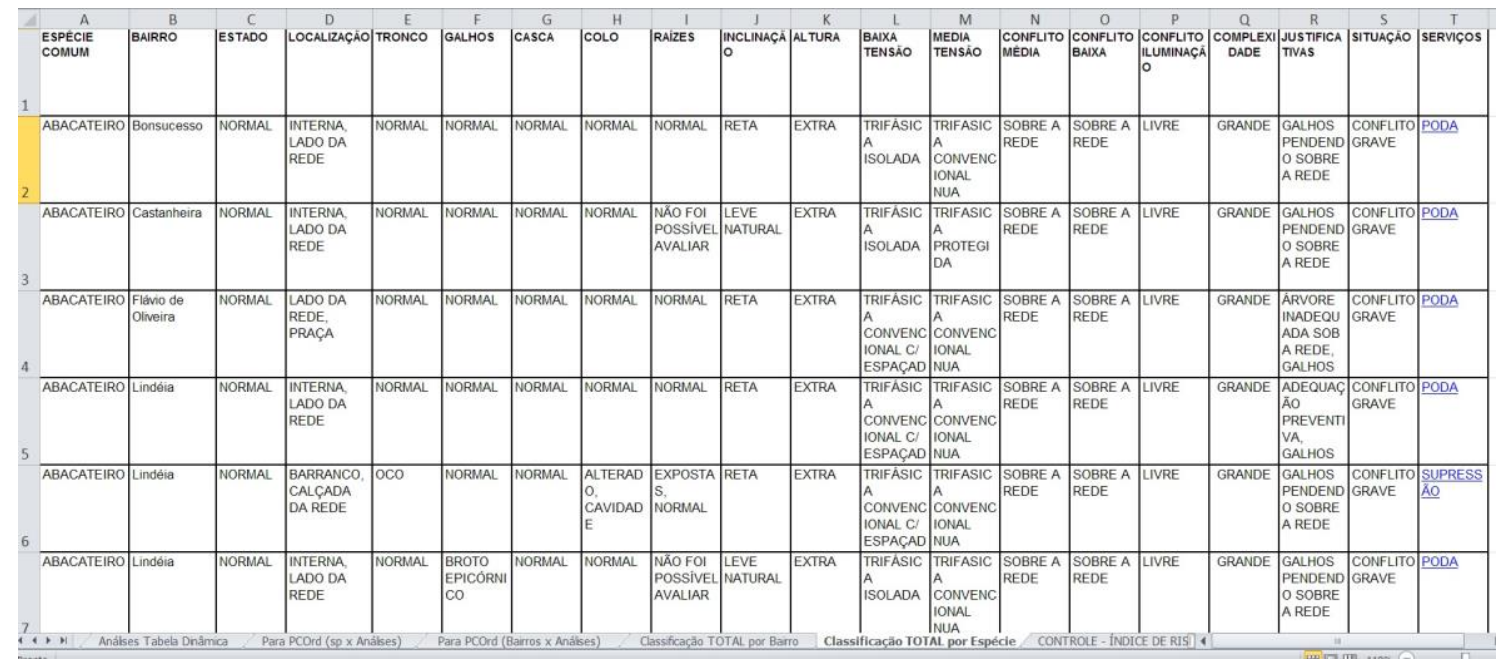

Os conjuntos de atributos comparados foram: Espécie x Altura (S.D., pequena, média, grande e extra alta); Espécie x Inclinação (eixo-inclinada, em direção à rede, forçando a fiação, leve natural, reta, S.D.); Espécie x Estado (morta, normal e senescente); Espécie x Complexidade (S.D., pequena, média e grande); Espécie x Conflito com redes de 13,8 KV (S.D., sob a rede, sob e sobre a rede e sobre a rede); Espécie x Situação (S.D., conflito grave, conflito leve, conflito médio, não relevante e de risco); Espécie x Situação das raízes (expostas com danos no asfalto e calçadas, seccionadas expostas com danos no asfalto e calçadas, dano na calçada, expostas com danos nas calçadas, seccionadas expostas com danos nas calçadas, normal com danos nas calçadas, seccionadas com danos nas calçadas, expostas, normal e expostas, S.D., normal e seccionadas); Bairro $x$ Altura; Bairro x Inclinação; Bairro x Estado; Bairro x Complexidade; Bairro x Conflito com redes de 13,8 KV; Bairro x Situação fitossanitária; Bairro x Situação das raízes.

Foi feita uma adaptação da planilha para a análise no PCOrd conforme o padrão da Figura 2, o que permitiu ser analisada com o objetivo de encontrar alguma relação, mesmo que em princípio técnicas de classificação julguem necessária a padronização de que as espécies devem ser dispostas nas linhas e as parcelas nas colunas. 
Figura 2. Planilhas Excel e PCOrd para análise dos conjuntos de atributos. Em destaque a planilha "Espécie versus Altura"

Figure 2. Excel worksheet to analysis of sets of atributes. In the spotlight the worksheet "Species versus Height"

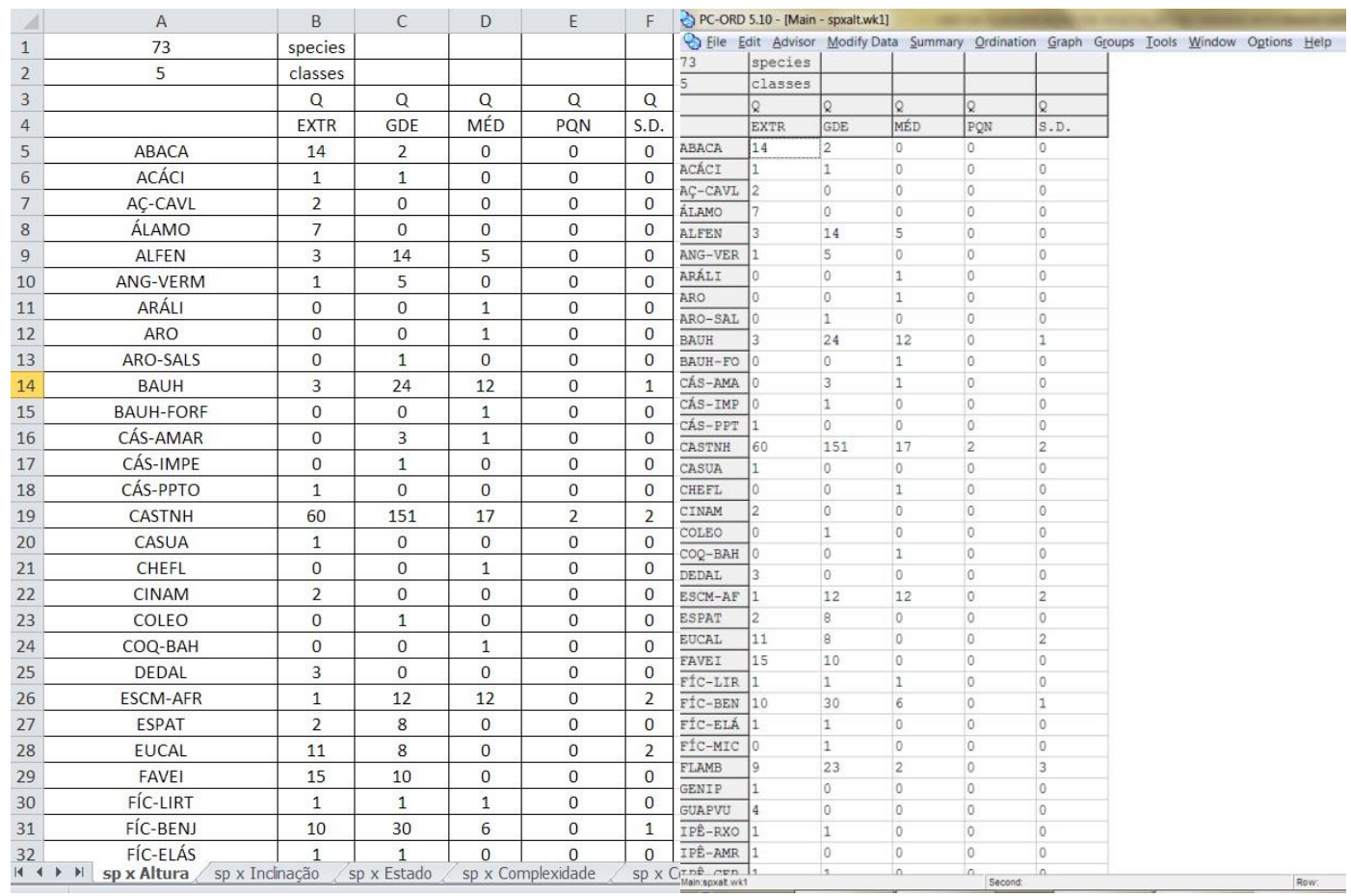

\section{RESULTADOS E DISCUSSÃO}

\section{Serviços e rotinas em manejo de vegetação na CEMIG}

Considerando-se a necessária adequação das redes de distribuição de energia elétrica com a arborização urbana, torna-se imprescindível um estudo aprofundado sobre os locais onde serão feitas as intervenções nas espécies florestais e, consequentemente, executados os mais diversos serviços.

Assim, visando compreender os motivos de tais ações, com melhorias para a população e otimização de custos para as companhias energéticas, são gerados relatórios das principais demandas e ocorrências de desligamentos de energia elétrica que têm a árvore como causa. Em dados extraídos do Premiar (Tabela 1), houve uma evolução crescente de desligamentos de energia que tiveram as árvores como causa entre 2007 e 2009 (quando foi criado o programa). Porém, a partir de 2010 houve uma redução muito eficiente, de pelo menos $80 \%$ dos desligamentos, o que pode ser explicado pelas variadas ações do programa na capital de Minas Gerais. 
Tabela 1. Interrupções no fornecimento de energia elétrica na cidade de Belo Horizonte entre 2007 e 2011. Ocorrências que tiveram árvores como causa. Adaptado de CEMIG, 2011

Table 1. Interruptions in the supply of electricity in the city of Belo Horizonte-MG (Brazil) between 2007 and 2011. Results that had trees as cause. Adapted of CEMIG, 2011

\begin{tabular}{cc}
\hline Ano & Número de ocorrências \\
\hline 2007 & 1.633 \\
2008 & 1.816 \\
2009 & 2.225 \\
2010 & 1.840 \\
2011 & 324 \\
\hline
\end{tabular}

Primeiramente foi feita uma análise na técnica de classificação por TWISPAN da Regional Barreiro com a finalidade de se verificar o comportamento das 73 espécies encontradas de acordo com sua localização nos 46 bairros. As divisões dos grupos são feitas de acordo com quocientes de correlação ou autovalores das variáveis coletadas, não sendo interessante a análise dos grupos formados em divisões com os valores menores ou igual a 0,3 , pois não permitem inferir diferenciações significativas.

Analisando-se o dendrograma da Figura 3, verificou-se a separação do bairro Vila Nova de todos os outros. Ao analisar a planilha original foi percebido que houve a presença de somente uma espécie (Genipapo) naquele bairro a ser suprimida, pois causava conflito grave. Era de se esperar que o programa a classificasse como espécie indicadora, pois, de acordo com Felfili (2007), as espécies indicadoras correspondem a um grupo característico e é uma particularidade do TWISPAN, colocando-o bastante útil quando da identificação de espécies de uma comunidade em particular. 
Figura 3. Dendrograma construído no Power Point a partir dos resultados obtidos no PCOrd da classificação TWISPAN da Regional Barreiro, com 46 Bairros e 73 espécies

Figure 3. Dendrogram built in the Power Point program from the Barreiro Regional PCOrd TWISPAN classification results, with 46 neighborhoods and 73 species

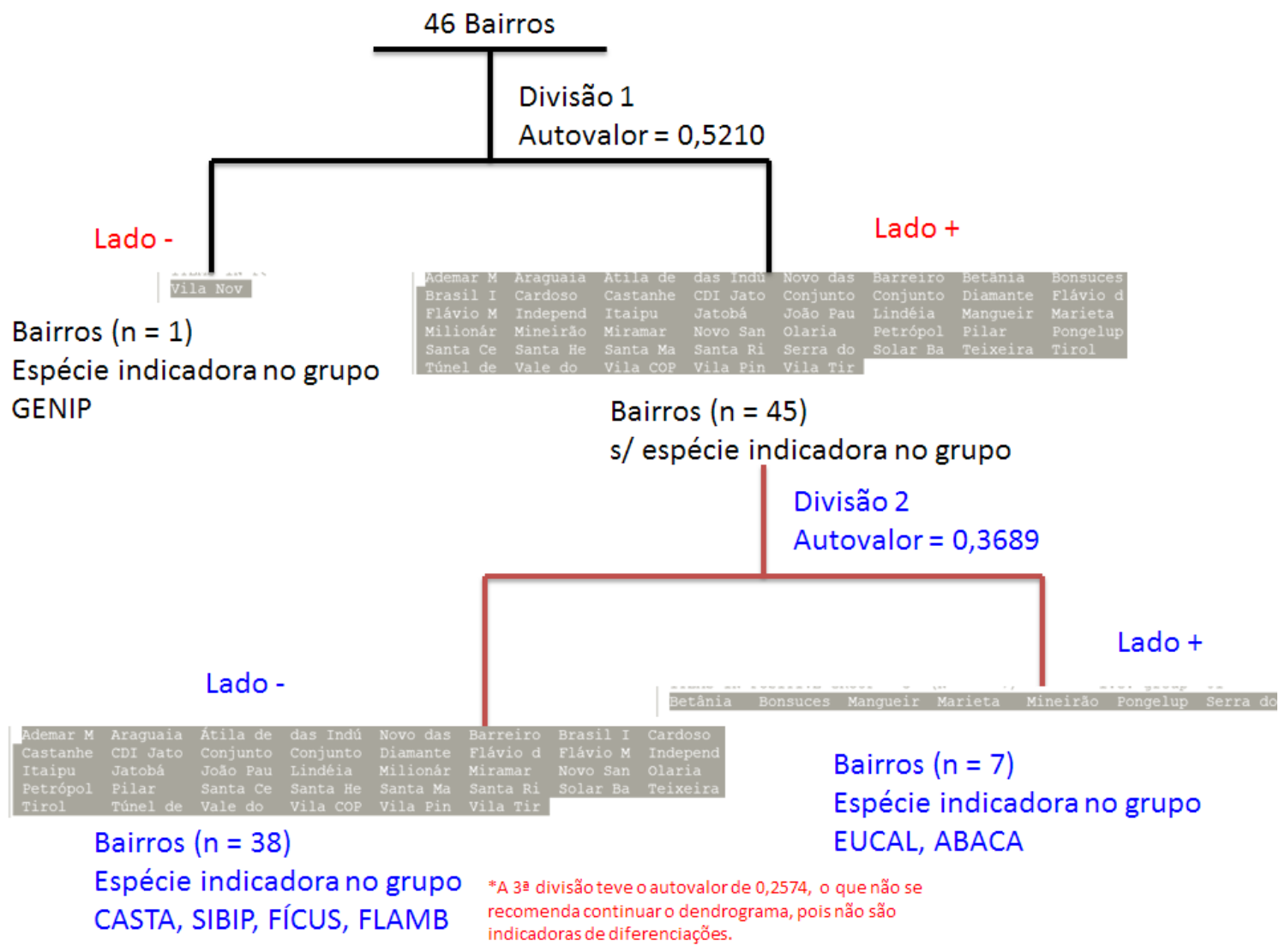

Continuando a análise do outro conjunto de bairros $(n=45)$ o programa fez a divisão de dois grupos, um com 38 bairros, tendo suas espécies indicadoras a castanheira, a sibipiruna, o fícus e o flamboyant, e outro com 7 bairros, sendo o eucalipto e 0 abacateiro suas espécies indicadoras.

Novamente ao analisar a planilha original, as espécies tidas como indicadoras nos dois grupos estiveram presentes na maioria dos bairros de cada conjunto. Esta resposta é de grande valia para as instituições que necessitam fazer o manejo da vegetação naqueles locais, uma vez que esforços podem ser concentrados nas espécies indicadoras, que são tidas como representativas do grupo. Logo, a análise do programa será extremamente necessária para se chegar ao conjunto de bairros em que a espécie está presente, permitindo ações de priorização de serviços de supressão ou substituição.

Como exemplo, sendo os eucaliptos, espécies inadequadas para o plantio em áreas urbanas, a instituição (prefeitura ou concessionária) poderia facilmente concluir que aquele 
grupo ou conjunto de bairros, apresenta o maior quantitativo da espécie e, por conseguinte, em caráter de urgência tomar as melhores ações de manejo daquela vegetação. Devido ao grande porte das espécies eucalipto e abacateiro (Divisão 2, lado +) e uma vez plantadas próximo ou debaixo da rede elétrica, é inevitável o contato da vegetação com a rede, ocasionando perdas e desligamentos. Se a concessionária, em parceria com o poder público, utilizasse softwares de análise da vegetação com a referida técnica, os mesmos iriam priorizar os bairros com maiores incidências (verificar os sete bairros descritos na Figura 3), com ações de substituição de espécies e poda de galhos conflituosos por exemplo.

A classificação TWISPAN para os atributos Altura versus Espécie resultaram nas Figuras 4 e 5 .

Figura 4. Dendrograma construído no Power Point a partir dos resultados obtidos no PCOrd da classificação TWISPAN da Regional Barreiro, com os atributos altura versus espécie

Figure 4. Dendrogram built in the Power Point program from the Barreiro Regional PCOrdTWISPAN classification results, with the attributes of height versus species

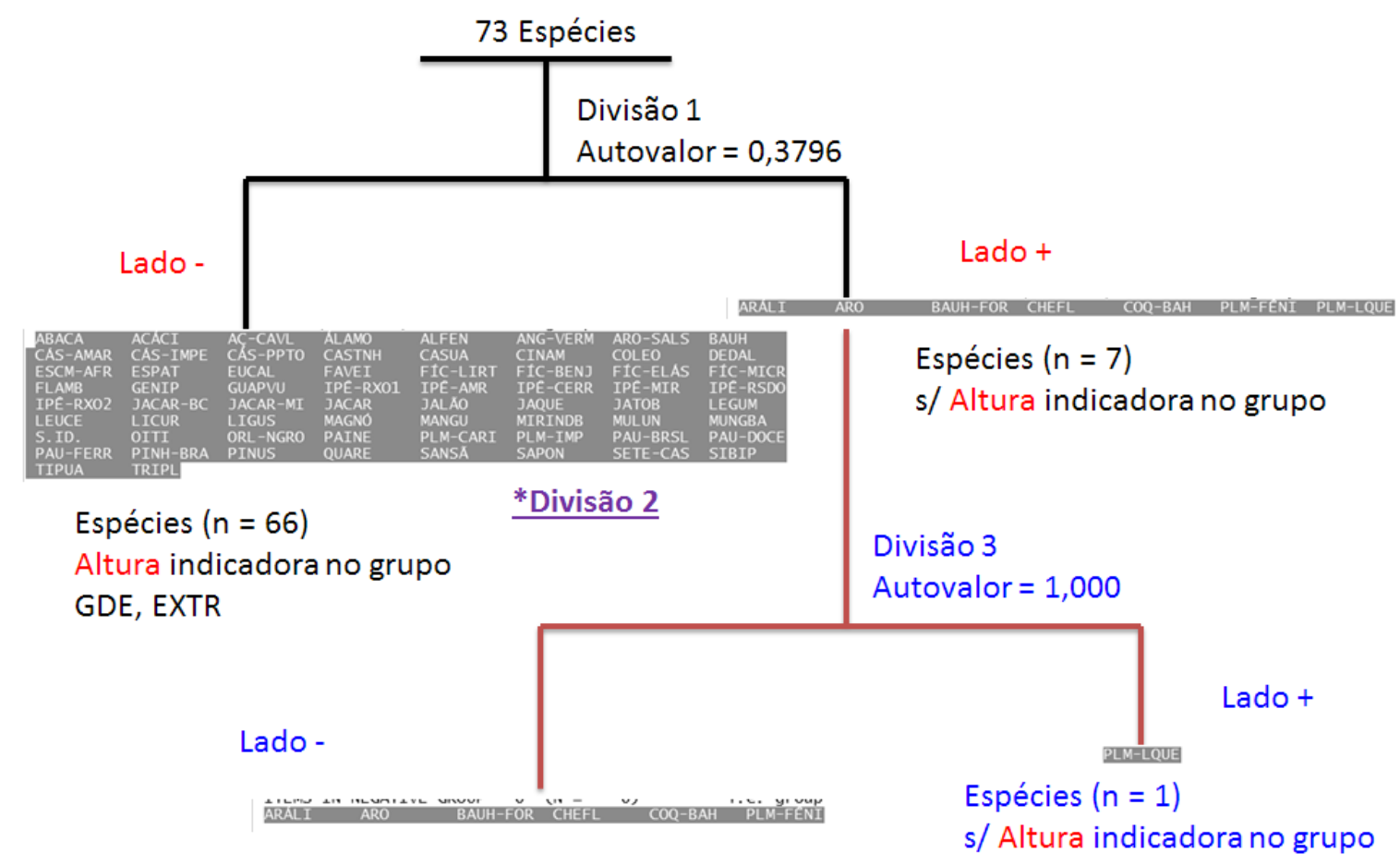

Espécies $(n=6)$

Altura indicadora no grupo

MÉD 
Figura 5. Dendrograma construído no Power Point a partir dos resultados obtidos no PCOrd da classificação TWISPAN da Regional Barreiro, com os atributos altura versus espécie

Figure 5. Dendrogram built in the Power Point program from the Barreiro Regional PCOrd TWISPAN classification results, with the attributes of height versus species.

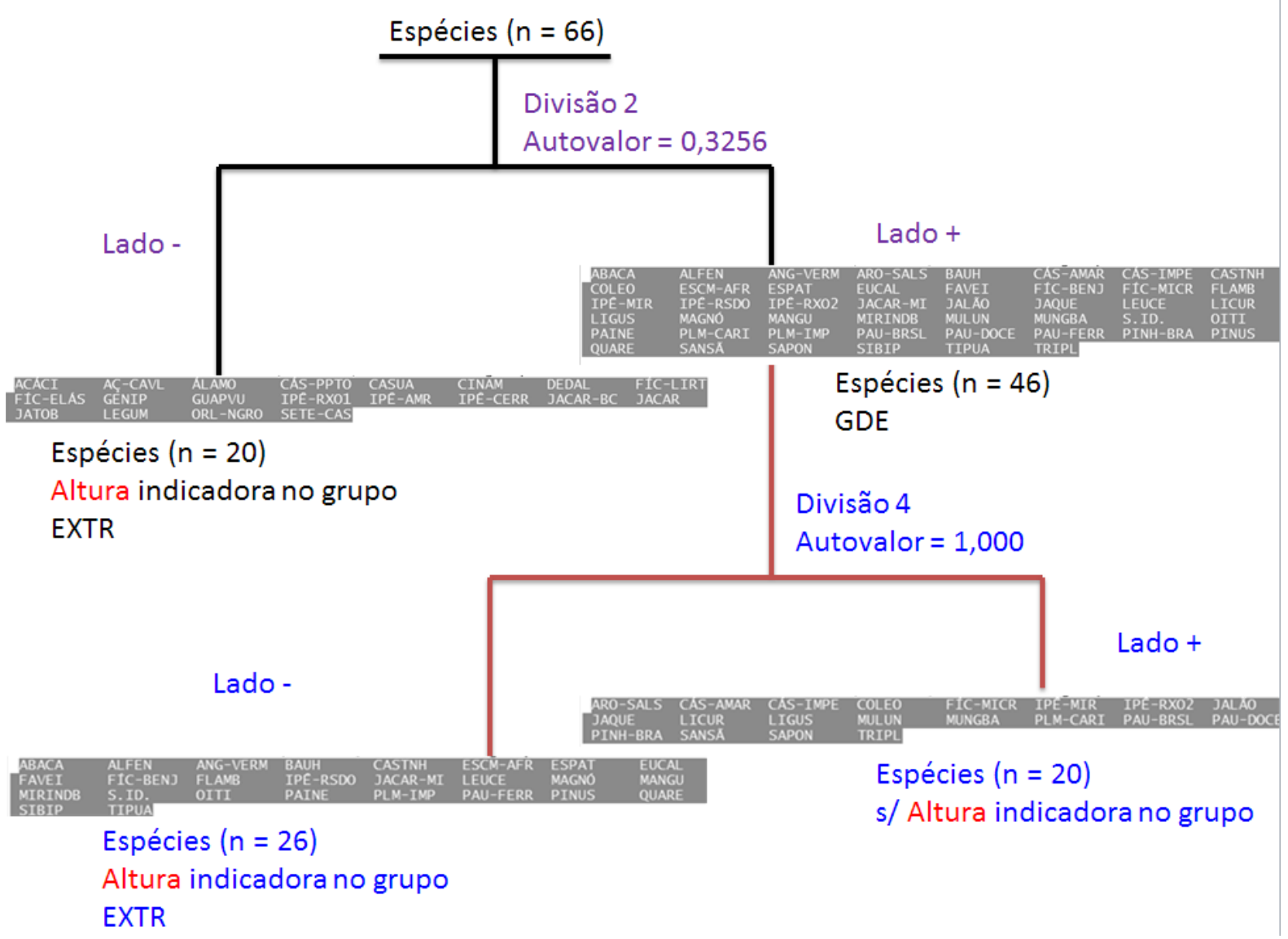

Pela análise das Figuras 4 e 5, mesmo não finalizando toda a construção do dendrograma, percebe-se que a classificação se deu no sentido de separar as espécies com os atributos "altura" em grupos preferenciais. Nesse ponto se faz uma ressalva, pois o programa trabalha com "espécie" indicadora. Como no conjunto de dados a espécie é um dos vários atributos, optou-se pela adaptação do termo espécie indicadora por altura indicadora. Do mesmo modo quando foi feito o estudo relativo aos conflitos com a rede elétrica, ficando o termo "conflito indicador" o seu substituinte.

Na primeira divisão (Figura 4) separaram-se aquelas espécies que continham menor quantidade geral (1), com altura média e pequena, colocando-as à parte no grupo positivo (Lado +). O grupo negativo (Lado -), com 66 espécies distribuídas entre as alturas grande e extra-grande foi dividido (Divisão 2). Nesse estudo havia 87,19\% de indivíduos classificados em alturas "grande" e "extra-grande", 10,10\% de indivíduos classificados em alturas "média" 
e "pequena", e 2,71\% não classificados ou "S.D.". Logo, a segunda divisão foi bem representativa, pois foram separadas as espécies que continham a maior quantidade de indivíduos nas duas maiores classes: grande e extra-grande.

Nesta nova divisão (Figura 5), espécies preferenciais para altura extra-grande (alturas que ultrapassam os limites dos postes ou estruturas elétricas, em média, acima de 10 metros) foram separadas daquelas para altura grande, o que pode ser enxergado pelas concessionárias de energia elétrica como um bom resultado, indicando os locais prioritários para poda ou substituição de árvores de grande porte. Nesse caso, é interessante que outros parâmetros sejam considerados, ou até mesmo analisados como uma segunda camada, pois caso haja a informação agrupada da espécie, seu porte e sua localização, a identificação seria mais eficaz bem como o manejo seria facilitado.

A utilidade deste método para as análises em arborização urbana, após novas tentativas de soluções direcionadas ao tema, trará muitos benefícios para programas como o Premiar, uma vez que serão permitidas ações de priorização de serviços, como poda de árvores grandes, extra-grandes etc. em locais diferenciados, ou bairros.

Para finalizar, uma análise foi feita para verificar o comportamento dos grupos de espécies em atingir a rede elétrica, ou seja, aqueles grupos que estão em conflito com a rede e que podem ser indicadores de ações prioritárias. A Figura 6 mostra que realmente se retira grande utilidade nesta classificação, a qual separa grupos interessantes que permitem análises para intervenções na rede, como poda das árvores que estão tocando a rede de média tensão (13,8 KV), por exemplo. 
Figura 6. Dendrograma construído no Power Point a partir dos resultados obtidos no PCOrd da classificação TWISPAN da Regional Barreiro, com os atributos conflito com a rede de 13.800 volts versus espécie

Figure 6. Dendrogram built in the Power Point program from the Barreiro Regional PCOrdTWISPAN classification results, with the attributes of 13.800 volts electric network versus species

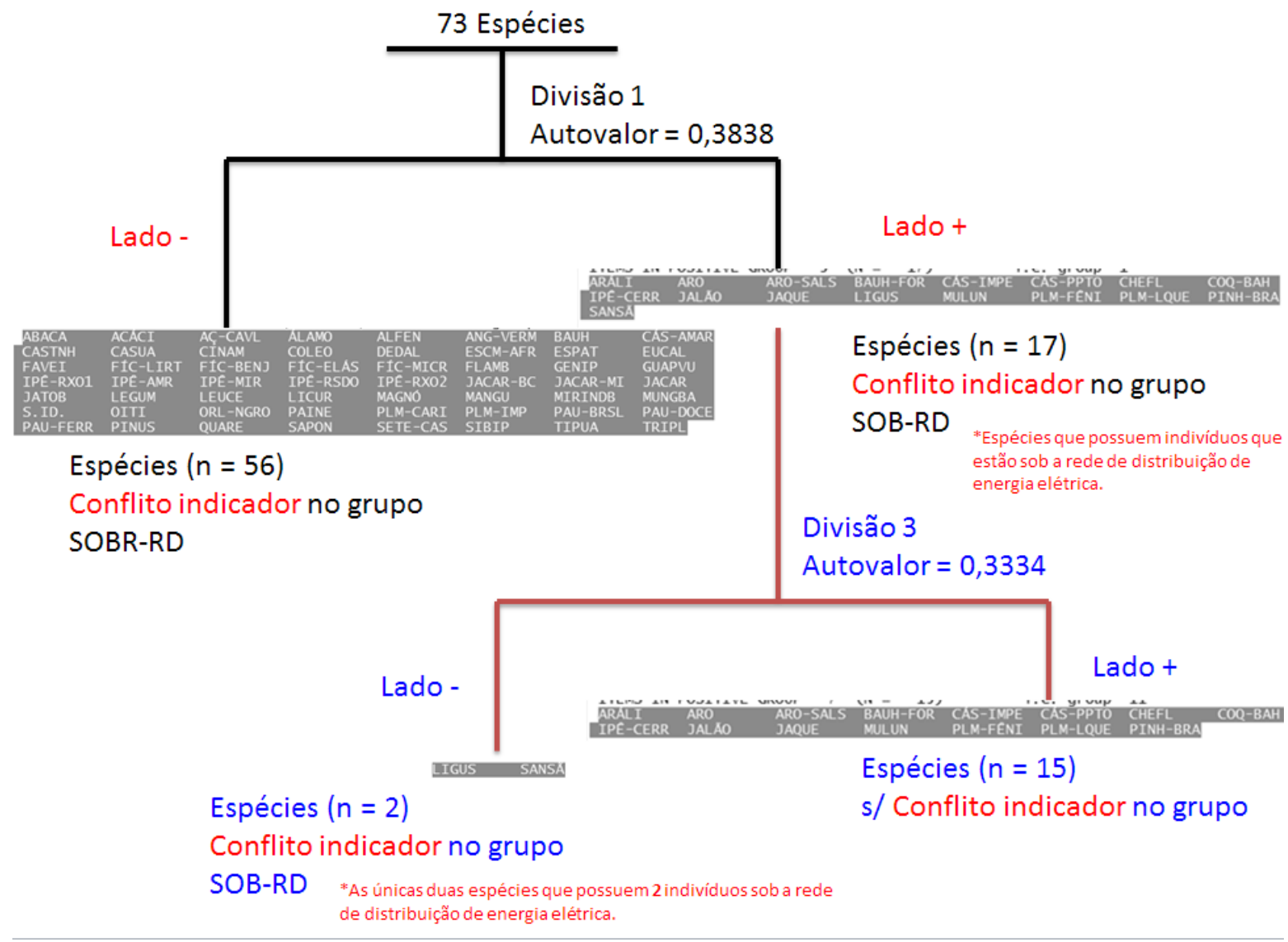

Os resultados poderiam ser comparados com análises de outros atributos, como atributos de Sistemas de Informação Geográfica (SIGs), tipos de solos urbanos, localização da árvore na via pública (na calçada, dentro do lote, em barrancos, etc.), estado sanitário do indivíduo, como uma tentativa de se alinhar mais dados para justificar ações no manejo de vegetação urbana, como substituição de espécies inadequadas, poda de galhos conflituosos, remoções de indivíduos arbóreos, dendrocirurgias, corte de árvores em estado sanitário comprometedor e outras. 


\section{CONCLUSÕES}

- A classificação da vegetação é um tema amplo e de grande valia para a pesquisa nas áreas de Engenharia Florestal, Ecologia e Ciências Ambientais em geral e são amplas as possibilidades de tratamento de dados de vegetação segundo técnicas de classificação propostas na literatura científica;

- Os resultados obtidos a partir destas análises de dados podem prover diversas utilidades e o principal objetivo destes estudos é o de descrever a vegetação, havendo possibilidades de utilização da classificação da vegetação em áreas do conhecimento que estão em pleno desenvolvimento, como por exemplo, a arborização urbana ou manejo de vegetação em áreas urbanas;

- Sugere-se que as concessionárias de energia elétrica deveriam cada vez mais incluir em seus sistemas, metodologias de análises multivariadas para atributos de manejo de vegetação. Como demonstrado no trabalho, o método TWISPAN forneceu informações bastante úteis para o manejo de árvores debaixo de redes elétricas, permitindo ações de priorização de serviços em bairros amplos e com grandes complexidades. Serviços prioritários de poda ou substituição de árvores de grande porte são meros exemplos do que os métodos de classificação da vegetação podem fornecer à essas instituições.

\section{AGRADECIMENTOS}

À Gerência de Gestão do Meio Ambiente da Distribuição da CEMIG, a qual disponibilizou os dados para que este trabalho fosse desenvolvido.

\section{REFERÊNCIAS}

CALIFORNIA NATIVE PLANT SOCIETY - CNPS. Reports. Disponível em: <https://cnps.org/cnps/vegetation /reports.php>. Acesso em: 14 maio 2012.

CHUMAN, T.; ROMPORTL, D. Multivariate classification analysis of cultural landscapes: An example from the Czech Republic. Landscape and Urban Planning, v. 98, p. 200-209, 2010.

CUPERTINO, M.A.; EISENLOHR, P.V. Análise florística comparativa da arborização urbana nos campi universitários do Brasil. Bioscience Journal, v.29, n.3, p. 739-750, 2013. 
DAI, X.; PAGE, B.; DUFFY, K.J. Indicator value analysis as a group prediction technique in community classification. South African Journal of Botany, v. 72, p. 589-596, 2006.

DOLAN, B.J.; PARKER, G.R. Ecosystem classification in a flat, highly fragmented region of Indiana, USA. Forest Ecology and Management, v. 219, p. 109-131, 2005.

FELFILI, J.M. Análise multivariada em estudos de vegetação. Brasília, Departamento de Engenharia Florestal, 2007.

INTERNATIONAL ASSOCIATION FOR VEGETATION SCIENTISTS - IAVS. The IAVS Vegetation Classification Methods Website. Disponível em: <http://sites.google.com/site/vegclassmethods/>. Acesso em: 14 maio 2012.

KENT, M.; COKER, P. Vegetation description and analysis. A pratical approach. Belhaven Press London, 1992.

MjM Software Design. PC-ORD Information. Disponível em: <http://home.centurytel.net/ mjm/pcordwin.htm>. Acesso em: 10 abr. 2012.

PILLAR, V.D. How sharp are classifications? Ecology, v. 80, n. 8, p. 2508-2516, 1999.

PILLAR, V.D. Variações espaciais e temporais na vegetação; métodos analíticos. UFRGS, Departamento de Botânica, 1996. Disponível em: http://ecoqua.ecologia.ufrgs.br. Acesso em: 14 maio 2012.

PROGRAMA ESPECIAL DE MANEJO INTEGRADO DE ÁRVORES E REDES. In: COMPANHIA ENERGÉTICA DE MINAS GERAIS - CEMIG, 2012. Disponível em: $<$ http://www.cemig.com.br/sustentabilidade/programas/ambientais/Premiar/Paginas/premiar. aspx>. Acesso em: 20 mai. 2012.

ROCHA, R.T.; LELES, P.S.S.; NETO, S.N.O. Arborização de vias públicas em Nova Iguaçu, RJ: o caso dos bairros Rancho Novo e Centro. Revista Árvore, v.28, n. 4, p.599-607, 2004.

SANTOS, E. Avaliação quali-quantitativa da arborização e comparação econômica entre a poda e a substituição da rede de distribuição de energia elétrica da região administrativa Centro-Sul de Belo Horizonte-MG. 2000, 219f., Tese (Doutorado em Engenharia Florestal), Programa de Pós-graduação em Engenharia Florestal - Universidade Federal de Viçosa, Viçosa, MG, 2000.

WILDI, O. Data analysis in vegetation ecology. John Wiley e Sons, Wiley-Blackwell, Ltd, 2010. 